\title{
Thermal Comfort Performances of a Green Roof Modular System Fixed on Gable Roofs
}

\author{
Sirisena A.G.D.S. ${ }^{1}$, Halwatura R.U. ${ }^{2}$, Herath H.M.P.I.K. ${ }^{1}$, Jayasinghe G.Y. ${ }^{1 *}$ \\ ${ }^{1}$ Department of Agricultural Engineering, Faculty of Agriculture, University of Ruhuna, Sri Lanka \\ ${ }^{2}$ Civil Engineering Department, Faculty of Engineering, University of Moratuwa, Sri Lanka \\ *victorlion3000@gmail.com
}

\begin{abstract}
Urbanised areas are tend to heat up more than neighborhoods as consequences of global warming and urban heat island effect due to high built up areas. Moreover, buildings are the most energy consumptive assets in energy systems. Green roofing is a popular strategy for passive cooling of buildings in present green building industry and it has become the best solution to overcome problems related to thermal comfort. A conventional green roof made up with the combination of vegetation layer, growing media, drainage layer and root barrier layer add a huge weight up on the existing roofs. Hence, green roof modular system is more efficient in cost and performances basis with less weight as separated by prefabricated or non-prefabricated novel method. This study evaluated the effect of fixed green roof modular system to an existing building to ensure the thermal comfort performances of outdoor and indoor conditions of the building by innovating portable frame network and new growing media for green modules with low weight, low cost and easy maintenance. Developed module's unit weight was $400-450 \mathrm{~g}$ and it covered an area of $412.5 \mathrm{~cm}^{2}$. It was fabricated with fiber glass and a frame network was developed using canvas-rubber mixed materials with a unit weight of $622.5 \mathrm{~g}$. Growth medium was prepared by using rubber and coir mixed material. Ipomea aquatica, Centella asiatica and Alternanthera sessilis were used as testing vegetation for the developed green roof modules. Leaf area (LA) and number of leaves were used as the parameters to select the best plant variety for the green roof. Subsequent thermal performance parameters of the green roof were analysed by comparing it with a normal roof of the same building. Leaf area of $C$. asiatica was significantly higher than I. aquatica and $A$. sessilis. Plant height, LA and number of leaves are the main factors that control the penetration of solar radiation; hence it influences the temperature. By considering statistical analysis and above facts, $C$. asiatica was selected as the best plant variety for the modules. A maximum indoor and outdoor temperature difference was reported after implementing the green roof modular system as $3^{\circ} \mathrm{C}$. Control roof showed a maximum temperature difference of $2.3^{\circ} \mathrm{C}$ between indoor and outdoor. The maximum relative humidity difference between inside and the outside roof was recorded as $3.5 \%$ while control roof was given 3.3\%.Therefore green roof modular system developed with fiberglass and frame network with coir-rubber mixed growing media for Centella asiatica can be suggested to enhance the thermal comfort of indoor and outdoor environments.
\end{abstract}

Keywords: Green roofs, Green roof modules, Growing medium, Leaf area, Portable frame network

Proceedings of the $22^{\text {nd }}$ International Forestry and Environment Symposium 2017 of the Department of Forestry and Environmental Science, University of Sri Jayewardenepura, Sri Lanka 